\title{
Adult Non-Hodgkin Lymphoma
}

National Cancer Institute

\section{Source}

National Cancer Institute. Adult Non-Hodgkin Lymphoma. NCI Thesaurus. Code C7704.

Non-Hodgkin lymphoma occurring in adults. 